\title{
Evaluation of Mental Health Integration in Primary Health Care in View of Participants and Rural Health Workers of Dezful, Khuzestan
}

\author{
Mohammad Hossein Khosrotaj ${ }^{1}$; Mansour Zahiri ${ }^{1,}$; Sheyda Javadipoor ${ }^{1}$; Seyyd Mahmood \\ Latifi $^{2}$ \\ ${ }_{1}^{1}$ Musculoskeletal Rehabilitation Research Center, Ahvaz Jundishapur University of Medical Sciences, Ahvaz, IR Iran \\ 2 Department of Biostatistics, School of Public Health, Ahvaz Jundishapur University of Medical Sciences, Ahvaz, IR Iran \\ ${ }^{*}$ Corresponding author: Mansour Zahiri, Musculoskeletal Rehabilitation Research Center, Ahvaz Jundishapur University of Medical Sciences, Ahvaz, IR Iran . Tel: +98-9122143979, \\ E-mail:man_zahiri@yahoo.co.uk
}

Received: February 5, 2015; Revised: April 15, 2015; Accepted: April 28, 2015

\begin{abstract}
Background: Evaluation and determination of different achievements of interventions in health care is one of the important responsibilities of the health system.

Objectives: The aim of present study was to evaluate the integration of mental health program in the primary health care (PHC) system in rural areas of Dezful district in view of participants and health workers.

Patients and Methods: In this descriptive-cross sectional research, which was done in rural areas of Dezful during year 2014, the main indexes of mentioned integration such as knowledge, attitude and performance of physicians, health workers and participants were measured. The data collection instrument was valid and reliable questionnaires, which are often used by the mental health department of the health ministry. Validity and reliability of questionnaires have frequently been confirmed by researchers in different studies. The study population included all 19 rural physicians, 89 health workers and a random sample of 15 - 60 year-old participants in the health network of Dezful. Frequency of distribution and computation of central and distribution indexes were used for data analysis.

Results: The amount of physicians' knowledge was about 50\%, while the rate of health workers' knowledge was $62 \%$. The rate of health workers' attitude was $92 \%$, while the rate of participants' knowledge was $50 \%$ and the rate of participants' attitude was $19 \%$. Consequently, the integration of mental health in primary health care system of rural areas of Dezful district has been relatively successful.

Conclusions: The integration of mental health into primary health care is an important priority in the Iranian health system. Monitoring and evaluation of this strategic project to remove its weaknesses is essential.
\end{abstract}

Keywords: Evaluation; Mental Health; Primary Health Care

\section{Background}

The prevalence rate of mental disorder symptoms has been estimated at $21 \%$ in the population above 15 years old (1). Mental disorders are at least as disabling as cancer or heart disease in terms of lost productivity and premature death (2). This issue has been emphasized on healthy man's performance program and overall health in the Iranian 1404 vision. Also, policies have emphasized on the development of mental health parameters for students that encounter narcotics (3).

In many countries, including Iran, because of more attention to health problems, such as infections and epidemic diseases, the mental dimension of health, has been less noticed. Social and mental dimensions have been ignored as well. Mental disorders are second place with heart diseases after incidents as the most important disorders classification in Iran (4). According to the estimation of the World Health Organization, Harvard University, and World Bank about 13\% of total diseases are due to mental disorders. This rate has been estimated to increase to $15 \%$ by $2020(5,6)$.

High dispersion of rural centers in Iran, like many developing countries, has resulted only limited facilities of mental health available for rural habitants. Thus, many attempts have been made to integrate mental health in the primary health care (PHC) network. Although there are many problems in training psychiatrist and building new psychiatric hospitals in different areas, the integration of mental health in primary health care has been considered practical and advantageous. This strategy has been considered in many countries such as India, Greece and Philippine and successful results have been reported by previous studies. On the other hand, the success of the PHC network indicated the importance of this method in extending mental health services $(7,8)$. According to Zambia's government authorities, many diseases have been prevented based on the primary health care system.

Copyright (C) 2015, Ahvaz Jundishapur University of Medical Sciences. This is an open-access article distributed under the terms of the Creative Commons Attribution-Non Commercial 4.0 International License(http://creativecommons.org/licenses/by-nc/4.0/) which permits copy and redistribute the material just in noncommercial usages, provided the original work is properly cited. 
primary health care is a vehicle for people to select their health care type (9).

Mental health services has been delivered to poor people by physicians, health personnel and health workers with integration in the primary health care system in the nearest place of their life and the farthest place of rural areas in country (10). Mental health concept is the most general concept of health. Integration of mental health in PHC is the most fundamental recommendation of health reforms in all health systems (11). In 1985, the Islamic Republic of Iran reformulated the mental health program of the country. The general purpose of this program was the integration of mental health in primary health care to support, maintain and increase the level of mental health in people especially the habitants of rural areas. The first experimental stage of this program was an investigation of outcome of the PHC system in Isfahan and Chaharmahal o Bakhtiari provinces during 1988 (5). This national program was evaluated during different times and locations and curative cases have been reported (5, 12,13). There are indexes for evaluation of PHC integration such as knowledge, attitude and performance of physicians, health workers and participants. Special features of Dezful such as high temperature, air pollution, the existence of many tribes due to its agricultural nature, and imposed war for eight years with the most rockets striking this location during the war, necessitate the careful evaluation and investigation of the mental health integration project in the PHC system.

\section{Objectives}

The present study aimed to evaluate the mental health integration program in the PHC system in rural areas of Dezful district in view of participants and health workers. Although many studies have been done to determine morbidity rate considering mental health of patients in villages, the questionnaires that were used in this study have been rarely used by other studies. In this study, knowledge, attitude and performance of the study population were evaluated as the main indexes of PHC integration while statistic performance forms were used in the health centers of Dezful.

\section{Patients and Methods}

Rural health workers, physicians who work in rural health centers and participants who are service receivers in villages of Dezful district were studied in this descriptive-cross sectional research. In this study, knowledge, attitude and performance of participants, health workers and physicians were assessed by questionnaires relevant to evaluation of the mental health program. The applied questionnaires in this study have been approved by the mental health department of the health ministry (5). Validity and reliability of questionnaires have been confirmed by previous studies $(4,5,7,10)$.

Physicians who completed the questionnaires had participated in the National Family Physician Program. They had also contributed in the mental health project in rural areas. In order to measure attitude and knowledge of participants, ten candidates with an age range of 15 - 60 years from each village were randomly selected and asked to complete the questionnaires. If the participant was illiterate, other family members were asked to complete the questionnaire. Finally 431 participants, 89 health workers and 19 Physicians completed the related questionnaires.

\section{Results}

The purpose of the present study was to evaluate the mental health program integration in PHC system in view of participants and health workers. There are indexes for evaluation of PHC integration such as knowledge, attitude and performance of physicians, health workers and participants. Demographic information of the studied population is showed in Table 1.

Physicians achieved 50.8\% knowledge scores, 94.5\% followed the patients' mood, and $94.5 \%$ supervised the health workers' tasks. Also, these physicians obeyed the privacy principles when treating patients in $72 \%$ of cases. In other words, physicians achieved a little more than half of the knowledge score and 94.5\% performed their task well in the mental health sector. Information showed that physicians were unable to diagnose psychoses and behavioral disorders in 33\% of children and 5.5\% of neuroses in adults. In this manner, they were unable to treat $44.5 \%$ of psychoses, $16.6 \%$ of neuroses, and $11 \%$ of epilepsy in adults, and 5.5\% of mentally retarded and behavioral disorders in children (Table 2).

Health workers achieved $64.4 \%$ and $92 \%$ for knowledge and attitude scores, respectively. During the six months prior to this study $22.7 \%$ of health workers instruction sessions were about mental health. There were also 59 physician instruction sessions for health worker. Frequency and rate of follow up of patients are presented in Table 4.

Table 1. Demographic Characteristics of Physicians, Health Workers and Population Under Study ${ }^{\text {a }}$

\begin{tabular}{lcccc}
\hline Variable & Gender & Age & $\begin{array}{c}\text { Occupation } \\
\text { Record }\end{array}$ & Total \\
\hline Physicians & $13(68.4)$ & $38.47 \pm 7.07$ & $63.5 \pm 39.77$ & 19 \\
$\begin{array}{l}\text { Health } \\
\text { workers }\end{array}$ & $34(38.2)$ & $35.7 \pm 7.3$ & $12.37 \pm 7.37$ & 89 \\
Participants & $166(38.5)$ & $29.78 \pm 9.33$ & & 431 \\
\hline
\end{tabular}

a data are presented as No. (\%) or Mean \pm SD.

Table 2. Summary of Physicians' Knowledge Scores

\begin{tabular}{cccccc}
\hline & Highest Score & Lowest Score & Mean \pm SD & Median & Mode \\
\hline Score & 8 & 4 & $6.11 \pm 1.1$ & 6 & 7 \\
\hline
\end{tabular}


Khosrotaj MH et al.

Table 3. Mean and Standard Deviation of Health Workers' Knowledge and Attitude

\begin{tabular}{lccccc}
\hline Variable & Mean \pm SD & Highest Score & Lowest Score & Median & Mode \\
\hline Knowledge & $56.03 \pm 11.68$ & 74 & 18 & 59 & 58 \\
Attitude & $15.63 \pm 1.4$ & 17 & 11 & 16 & 17 \\
\hline
\end{tabular}

Table 4. Frequency and Percentage of Patients With Mental Illness and Performance Type

\begin{tabular}{lcccccc}
\hline $\begin{array}{l}\text { Type of Diagnosed Disease } \\
\text { From the Previous Year }\end{array}$ & \multicolumn{2}{c}{ Acute Mental Patient $(\mathbf{n}=\mathbf{2 7 1})$} & \multicolumn{2}{c}{ Epilepsy $(\mathbf{n}=\mathbf{3 5 1})$} & \multicolumn{2}{c}{ Mentally Retarded $(\mathbf{n}=\mathbf{2 8 0})$} \\
\hline Performance Type & Follow up & Reference & Follow up & Reference & Follow up & Reference \\
\hline $\begin{array}{l}\text { Frequency of follow up } \\
\text { and reference }\end{array}$ & 263 & 122 & 299 & 131 & 232 & 59 \\
$\begin{array}{l}\text { Percentage of follow up } \\
\text { and reference }\end{array}$ & 97.5 & 45 & 85 & 37 & 82.8 & 21 \\
\hline
\end{tabular}

Table 5. Frequency and Mean of Health Workers Case-Finding and Compared With Expectable Case-finding in Families Under the Supervision

\begin{tabular}{lccc}
\hline & Frequency of Case Findings & $\begin{array}{c}\text { Rate of Case Findings in } \\
\mathbf{1 0 0 0} \text { Individuals }\end{array}$ & $\begin{array}{c}\text { Expected Limit of Case Findings in } \\
\mathbf{1 0 0 0} \text { Individuals }\end{array}$ \\
\hline Acute mental status & 271 & 2.1 & 1.5 \\
Low mental status & 504 & 4 & 5 \\
Epilepsy & 351 & 2.7 & 2.9 \\
Mentally retarded & 280 & 2.2 & 3.7 \\
\hline
\end{tabular}

Table 6. Status of Knowledge and Attitude of Participants $(\mathrm{n}=431)$

\begin{tabular}{lcccc}
\hline & Subjects & Highest Score & Lowest Score & Mean \pm SD \\
\hline Participants knowledge & 431 & 23 & 3 & $11.47 \pm 5.59$ \\
Participants attitude & 431 & 11 & 2 & $8.67 \pm 1.59$ \\
\hline
\end{tabular}

Frequency, rate and expected limit of case findings in 1000 patients are presented in Table 5. The mean of low mental status was higher than other disorders, which is justifiable considering the high prevalence this disease. This research showed that in $97.8 \%$ of family files, the patients' follow up form was completed. Also, 97.8\% of health houses sent the monthly statistics form of patients to health centers. In $93.5 \%$ of cases there were feedback form health houses. The percentage of participants' knowledge and attitude was $11.47 \%$ and $8.67 \%$, respectively (Table 6).

\section{Discussion}

The main purpose of the present study was to evaluate mental health integration program in PHC system in rural areas of Dezful. The main indexes of PHC integration such as knowledge, attitude and performance of population were measured. The results showed that all the studied physicians had passed the formal course of psychiatry. They had basic information that increased their knowledge about mental health. These results were similar to the report of Jenkins et al. about integration of mental health in primary health care (14). In this study physicians and health workers delivered mental health services. The mean of diagnosed patients was 11.86 in one thousand people, which was a little lower than the expected case-finding in our country (14.3 in one thousand people) (13). However, it was higher than reports on the mental health integration program in PHC system of Iran in 2009 (8.25 in one thousand individuals) (5). Also, the rate of case-finding of patients with mental illness in PHC system was 4.3 in the Sanandaj City (12), 10 patients in Andimeshk district (15) and 15.9 patients in Chahar mahal and Bakhtiari province per one thousand individuals (16). The study of Nicaragua revealed that doctors and nurses were reluctant to deal with young people with suicidal problems at the Primary Health Care system (17)

The studied physicians achieved a knowledge score of 50.87\%. This was similar to Bolhary and Ahadkhani's research (5) while it was in contrast to the findings of Taban and Armstrong $(18,19)$.

In investigating mental health instruction to participants, results showed that health workers were familiar with the mental health integration program for more than 9.2 years. The number of training sessions of every health worker was 211 from 930 about mental health under the supervision. During the past six months, $22.7 \%$ of 
total training sessions established by health workers were about mental health. Also, during many sessions, they were being taught by physicians and technicians. This result indicated the success of the mental health integration project in primary health services. Also, better results are surely expected with the elimination of limitations and utility of effective guidelines to attract more health workers in providing mental health service to rural participants. These results were similar to a mental health integration research in PHC system from Sri Lanka (20).

The mean of health workers answers to questions related to knowledge and attitude about mental health was $64.4 \%$ and $92 \%$, respectively. This can be taken into account as good level of knowledge and attitude particularly compared with previous studies $(13,21)$. Health workers had achieved a knowledge score of 52\% in the study of Faraj Pour et al. from Kerman. In cited research the mean score of attitude was reported as $79.8 \%$ (22), which is lower than this research results. Taban et al. from Isfahan showed that the mean of knowledge and attitude in health workers was $10.5 \%$ and $14.4 \%$, respectively (18). Another study reported more than 50\% knowledge score and 92\% attitude score in Sanandaj city that was approximately similar to the present research (12). Also our attitude score was similar while knowledge score was dissimilar with the study of Bolhary et al. $(5,23)$.

Results of this research have shown a rate of 2.1 per thousand acute mental patients, 2.7 in thousand epilepsy cases, 2.2 in thousand mentally retarded cases and 4 in thousand low mental status cases. These results were similar with the study of Bolhary et al. and comparable with the study of Mohet et al. (13) except for acute and low mental cases. It was similar with the study of Faraj Pour et al. except for mentally retarded cases (22). It was unlike evaluations by Mwape et al. (24) and Teiry et al. (12). It was similar to the study of Davasaz Irani et al. except for acute mental status patients (15).

Patient follow up is an important task for health workers. In the present research $97.8 \%$ of health workers completed the follow up form in family files; also, $97.8 \%$ health houses personnel sent monthly statistic forms of patients to health centers on the third day of each month. Furthermore, $93.5 \%$ of feedback forms of reference papers were kept at health houses. On the basis of these results, health workers performance was satisfactory in this context. Follow-ups performed one month after referral in this study was $97.5 \%$ for acute mental status, $85 \%$ for epilepsy and $82.8 \%$ for mentally retarded cases. These results were excellent and better than results of the national mental health evaluation (13).

The results indicated that participants achieved $18.8 \%$ and $49.8 \%$ for knowledge and attitude scores in mental health, respectively. These results were similar to the study of Taban et al. from Isfahan (18) and the evaluation of Teiry et al. from Sanandaj (12) and the survey of Cowan et al. from Bangalore (25). The survey of Bolhary et al., reported a similar mean score for participants attitude
(8.6\%) and dissimilar mean score for participants knowledge (20.5\%) (5).

Generally, on the basis of results, it can be said that the integration of mental health in PHC system of Dezful district has been successful, and existing problems are being resolved by training and retraining courses and more careful screening programs.

Integration of mental health in primary health care system is amongst the most important priorities of the Iranian health system. Evaluation of an implemented model of task sharing in mental health care in PHC of Ethiopia is underway and will yield important insights regarding acceptability and feasibility of this approach (26). We suggest that authorities and programmers should place more emphasis on this subject. Further steps should be taken in this valuable path by review of guidelines and retraining courses and more careful and periodic evaluations at different levels.

\section{Acknowledgements}

This paper was part of a Master of Science thesis in rehabilitation management (grant no: PHT-9309). This study was financially supported by the Ahvaz Jundishapur University of Medical Sciences. The authors would like to thanks the Dezful physicians, health workers and technicians for their cooperation and Research Deputy of AJUMS for their financial support.

\section{References}

1. Noorbala AA, Bagheri Yazdi SA, Yasamy MT, Mohammad K. Mental health survey of the adult population in Iran. Br J Psychiatry. 2004;184:70-3.

2. Prince M, Patel V, Saxena S, Maj M, Maselko J, Phillips MR, et al. No health without mental health. lancet. 2007;370(9590):859-77.

3. Ministry of Health and Medical Education.. Department of Health. Comprehensive program of developing country's mental health in 1390-1394.1.2012:1-16.

4. Bolhary J, Ahmad khaneha HR, Hajebi A, Bagher Yazdi A. The Evaluation of Mental Health Integration Program in Primary Health Care System of Iran. Psychiatry clin Psychol Mag Iran. 2012;17(4):271-8.

5. Bolhary J, Ahmad khaneha HR, Naser bakht M, Hajebi A. The evaluation of mental health integration in country in primary health care program and presenting good ways for advancing program. Iran J Psychiatry Clin Psychol. 2012;17(4):271-8.

6. Lund C, Tomlinson M, De Silva M, Fekadu A, Shidhaye R, Jordans $\mathrm{M}$, et al. PRIME: a programme to reduce the treatment gap for mental disorders in five low- and middle-income countries. PLoS Med. 2012;9(12):e1001359.

7. Bolhary J, Mohit A. The investigation of mental health integration in primary health care of Hashtgerd. Andisheh va Raftar Appl Psychol.;2((1,2)):16-24.

8. Hijazi Z, Weissbecker I, Chammay R. The integration of mental health into primary health care in Lebanon. Intervention. 2011;9(3):265-78.

9. Mwape L, Sikwese A, Kapungwe A, Mwanza J, Flisher A, Lund $C$, et al. Integrating mental health into primary health care in Zambia: a care provider's perspective. Int J Ment Health Syst. 2010;4(1):21.

10. Teiry F, Bolhary J, Asgharnezzhad A. The investigation of mental patient satisfaction and their families about mental health program in rural areas. Sci Res Q Soc Welfare. 2007;20(5):101-15.

11. Kigozi FN, Ssebunnya J. Integration of mental health into pri- 
mary health care in Uganda: opportunities and challenges. Ment Health Fam Med. 2009;6(1):37-42.

12. Teiry F, Bolhary J, Asghrnzhadfryd AA, Ghazizadeh A. The evaluation of mental health integration program in primary health care of rural areas in Sanandaj. Andeeshe va Rafter. 2003;12:403-9.

13. Mohet A, Bolhary J, Shahmohammadi D. The evaluation of mental health in country. Andeeshe va Rafter. 1996;3:4-16.

14. Jenkins R, Kiima D, Njenga F, Okonji M, Kingora J, Kathuku D, et al. Integration of mental health into primary care in Kenya. World Psychiatry. 2010;9(2):118-20.

15. Davasaz Irani R. The integration of mental health program in primary health care network of Andimeshk. Andeeshe va Rafter 2005;10(1.2):110-5.

16. Khadivi R, Shakeri M, Ghobadi S. The efficiency of mental health integration in primary health care: a ten-year study. Int J Prev Med. 2012;3(Suppl1):139-45.

17. Medina CO, Kullgren G, Dahlblom K. A qualitative study on primary health care professionals' perceptions of mental health, suicidal problems and help-seeking among young people in $\mathrm{Ni}$ caragua. BMC Family Practice. 2014;15(1):129.

18. Taban H, Zaman A. R. , Sadeghi B. . The evaluation of mental health program in the health houses level Curative health centers of rural areas in Isfahan. Res Med Sci.;7(2):108-11.

19. Armstrong G, Kermode M, Raja S, Suja S, Chandra P, Jorm AF. A mental health training program for community health workers in India: impact on knowledge and attitudes. Int J Ment Health Syst. 2011;5(1):17.

20. Jenkins R, Mendis J, Cooray S, Cooray M. Integration of mental health into primary care in Sri Lanka. Ment Health Fam Med. 2012;9(1):15-24.

21. Kauye F, Jenkins R, Rahman A. Training primary health care workers in mental health and its impact on diagnoses of common mental disorders in primary care of a developing country, Malawi: a cluster-randomized controlled trial. Psychol Med. 2014;44(3):657-66.

22. Faraj Pour M, Motamedi H, Bahramnejhad A. Health workers' knowledge, attitude, and performance of Kerman about mental diseases after 6 years the integration of mental health in primary health care system. J Oral Health Oral Epidemiol. 2000;6(2):97-104.

23. Abera M, Tesfaye M, Belachew T, Hanlon C. Perceived challenges and opportunities arising from integration of mental health into primary care: a cross-sectional survey of primary health care workers in south-west Ethiopia. BMC Health Serv Res. 2014;14(1):113.

24. Mwape L, Sikwese A, Kapungwe A, Mwanza J, Flisher A, Lund $\mathrm{C}$, et al. Integrating mental health into primary health care in Zambia: a care provider's perspective. Int J Ment Health Syst. 2010;4:21.

25. Cowan J, Raja S, Naik A, Armstrong G. Knowledge and attitudes of doctors regarding the provision of mental health care in Doddaballapur Taluk, Bangalore Rural district, Karnataka. Int J Ment Health Syst. 2012;6:21.

26. Lund C, Breen A, Flisher AJ, Kakuma R, Corrigall J, Joska JA, et al. Poverty and common mental disorders in low and middle income countries: A systematic review. Soc Sci Med. 2010;71(3):517-28. 